\title{
SISTEM INFORMASI PENERIMAAN PESERTA DIDIK BARU (PPDB) DAN REGISTRASI ONLINE BERBASIS WEBSITE PADA SMP NEGERI 6 PALANGKA RAYA
}

\author{
Dilla Ayu Dwipitaloka $\left.{ }^{\text {a. }}{ }^{*}\right)$, Enny Dwi Oktaviyani ${ }^{\mathrm{b}, 2}$, Felicia Sylviana $^{\mathrm{c}, 3}$, Licantik $^{\mathrm{d}, 4}$ \\ ${ }^{1)}$ Teknik Informatika Fakultas Teknik Universitas Palangka Raya, Jalan Hendrik Timang Kampus Tanjung Nyaho \\ 2) Teknik Informatika Fakultas Teknik Universitas Palangka Raya, Jalan Hendrik Timang Kampus Tanjung Nyaho \\ 3) Teknik Informatika Fakultas Teknik Universitas Palangka Raya, Jalan Hendrik Timang Kampus Tanjung Nyaho \\ 4) Teknik Informatika Fakultas Teknik Universitas Palangka Raya, Jalan Hendrik Timang Kampus Tanjung Nyaho \\ 1 dillaayudwipitaloka20@gmail.com ${ }^{*}$, ${ }^{2}$ Email : enny.obrien@ gmail.com, ${ }^{3}$ felicia.upr@ gmail.com, \\ 4 licantikmeteh@gmail.com \\ * corresponding author
}

ARTICLE INFO

\section{Keywords}

Website

PPDB

Registration

PHP

$M y S Q L$

\section{AB STRACT}

In writing this thesis report the author uses several waterfall methods. In this methodology several steps are taken to build a software, namely: needs analysis (analysis), design (design), coding (coding), testing (testing), and maintenance (maintenance), and using MySQL as a data storage medium, and using data collection methods, namely: observation methods, interview methods, library methods, documentation method and experiment method.

The results of this thesis are the processing of new student data and online registration based on the website is a series of data input activities, edit, delete, display reports of each data. Managing data using a computer is more beneficial when compared to managing data manually including the time needed to manage data shorter, looking for data faster and more accurately, storing data on a computer is more durable than manual methods, and the errors obtained are less due to computers has a very high accuracy to manage data.

\section{Pendahuluan}

SMP Negeri 6 Palangka Raya merupakan salah satu instansi yang bergerak pada bidang pendidikan yang berdiri sejak tahun 1984. SMP Negeri 6 Palangka Raya setiap tahunnya memiliki kegiatan penerimaan siswa baru. Pelaksanaan Penerimaan Peserta Didik Baru (PPDB) SMP Negeri 6 Palangka Raya merupakan kegiatan rutin untuk menjaring calon peserta didik baru yang berasal dari SD atau MI. Selama ini diketahui bahwa di SMP Negeri 6 Palangka Raya, sistem penerimaan siswa baru dan registasi ulang siswa baru masih dilakukan secara manual, yaitu calon siswa datang kesekolah dengan membawa syarat pendaftaran berupa SKHU (Surat Keterangan Hasil Kelulusan Nasional) asli, foto copy Kartu Keluarga, dan pas foto ukuran $3 \times 4$ sebanyak 4 lembar. Kemudian mengisi formulir pendaftaran yang telah disediakan panitia, dan mengembalikannya ke panitia. Panitia memverifikasi data, calon siswa yang datanya lolos verifikasi mengikuti tes seleksi, hasil seleksi akan diumumkan di SMP Negeri 6 Palangka Raya, calon siswa yang telah lolos seleksi melakukan daftar ulang dengan mengisi formulir yang telah disediakan panitia. Kemudian panitia memasukkan data siswa baru ke excel 2007. Pencatatan data yang dilakukan secara manual sering terjadi kekeliruan atau kesalahan maupun kehilangan data-data secara tidak sengaja serta pengambilan formulir pendaftaran yang dilakukan secara manual juga sering membuat calon siswa atau orang tua calon siswa harus mengantri panjang. Lamanya proses mengelola data berdampak langsung pada kinerja bagian panitia pelaksaan penerimaan siswa baru.

Hal tersebut menjadikan pendaftaran peserta didik baru (PPDB) dan registasi ulang tidak efektif dan efisien, dikarenakan banyak waktu, biaya dan tenaga yang terbuang untuk mendaftar 
menjadi siswa baru dan melakukan registasi ulang di sekolah tersebut. Oleh karena itu dibutuhkan sistem yang handal, efektif dan efisien yang memudahkan calon siswa baru yang ingin mendaftar disekolah tersebut serta melakukan pendaftaran ulang ketika dinyatakan diterima disekolah tersebut, dan juga memudahkan pihak sekolah dan panitia dalam pengelolaan data calon siswa baru dengan cepat dan efisien serta membuat laporan yang kredibel, sehingga pendaftaran siswa baru dapat terlaksana dengan baik.

\subsection{Penerimaan Peserta Didik Baru (PPDB)}

Dalam melakukan penyusunan agenda perencanaan dan penerimaan peserta didik baru (PPDB) langkah awal ini sangatlah penting, sebagai penentu kinerja sekolah pada masa yang akan datang. Agar kita dapat membuat agenda yang merupakan langkah awal dari proses penerimaan peserta didik. Karena penerimaan peserta didik baru (PPDB) yang lebih efektif kepala sekolah wajib membaca dan memahami dokumen-dokumen yang berkaitan dengan penerimaan peserta didik baru (PPDB) yaitu petunjuk Teknis penerimaan peserta didik baru (PPDB) yang dikeluarkan provinsi/kabupaten/kota khususnya tentang langkah-langkah atau prosedur penerimaan peserta didik baru (PPDB), yang biasanya mencangkup beberapa langkah yaitu langkah penyusunan rencana penerimaan peserta didik baru (PPDB), langkah pembentukan panitia penerimaan peserta didik baru (PPDB), rapat kerja dan pembagian tugas, proses pendaftaran, proses seleksi, proses penentuan calon terpilih dan proses daftar ulang [4]. [3] membahas tentang sebuah aplikasi web yang memudahkan siswa baru untuk proses penerimaan siswa baru seperti, pendaftaran online penerimaan siswa baru, pembelian formulir yang lebih mudah didapatkan diberbagai daerah diluar lingkungan SMA N 1 Pacitan berada. [5] membahas tentang sebuah aplikasi web untuk registasi ulang secara online dengan tujuan untuk mempermudah calon siswa dan petugas penerimaan siswa dalam melakukan registasi ulang. [2] membahas tentang sebuah aplikasi web agar terciptanya transparasi penerimaan siswa baru, kemudahan dalam seleksi siswa baru, memudahkan orangtua/siswa dalam proses pendaftaran. [6] sebelumnya telah melakukan penelitian mengenai sistem pembagian kelas baru di SMPN 9 Palangka Raya, penelitian yang dilakukan oleh [6] dapat digunakan setelah proses penerimaan siswa baru dan setelah proses daftar ulang.

\section{Metodologi}

Metode penelitian adalah kerangka teoritis yang dipergunakan untuk menganalisa, mengerjakan atau mengatasi masalah yang dihadapi. Sedangkan kerangka teoritis atau kerangka ilmiah adalah metode-metode ilmiah yang akan diterapkan dalam pelaksanaan tugas.

2.1. Studi Pendahuluan

\section{A. Lokasi Penelitian}

Penelitian ini mengambil lokasi pada SMP Negeri 6 Palangka Raya yang terletak di Letkol Seth Adji Palangka Raya, 73111.

B. Alat dan Bahan

1. Software tool dan bahasa pemrograman yang akan digunakan untuk pembuatan website adalah sebagai berikut:

a. PHP sebagai teknik dan bahasa pemrograman yang digunakan untuk membangun website [1].

b. MySQL sebagai media penyimpanan data.

c. $X A M P P$ sebagai aplikasi server.

d. Aplikasi pendukung lainnya yang digunakan untuk melakukan pemodelan dan perancangan sistem. 
2. Pemodelan sistem menggunakan data flow diagram (DFD) untuk mendeskripsikan dan menggambarkan pengguna, proses dan aktivitas pada sistem.

2.2. Metode Pengembangan Sistem

Metodologi pelaksanaan penelitian yang digunakan adalah metode siklus waterfall [4].

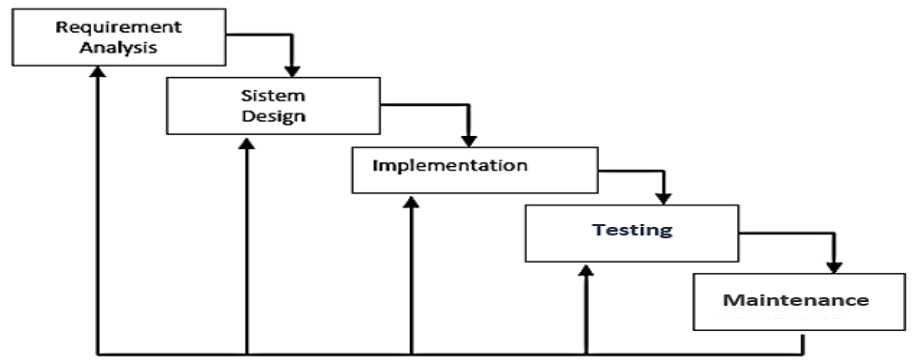

Gambar 3.1 Waterfall Modelling Roger S Pressman tahun 1997

\section{Analysis (Analisis)}

Langkah ini merupakan analisa terhadap kebutuhan sistem. Pengumpulan data dalam tahap ini bisa melakukan sebuah penelitian, wawancara atau studi literatur. Yang dilakukan adalah membuat analisis sistem yang ada kemudian dari sistem lama dibuat rekomendasi sistem baru, membuat diagram konteks, data flow diagram (DFD) dan entity relationship diagram (ERD).

2. Design (Desain)

Pada tahap ini, aktivitas yang dilakukan adalah, membuat desain sistem. Desain yang dibuat ada dua, desain interface dan desain database. Desain interface mulai dari menu awal saat kita membuka halaman utamanya akan muncul menu login, menu utama, sampai setiap fungsi yang ada di dalam sistem tersebut. Sedangkan, desain database adalah rancangan dari database yang akan digunakan.

\section{Implementation (Implementasi)}

Desain yang telah dibuat akan diubah kedalam suatu bentuk yang dapat dimengerti oleh sistem komputer, yaitu kedalam bahasa pemrograman melalui proses pengkodean, dengan menggunakan PHP. Tahap ini merupakan implementasi dari tahap desain yang akan dikerjakan oleh programmer.

4. Testing (Pengujian)

Setelah melakukan proses pengkodean maka akan dilakukan proses pengujian menggunakan blackbox testing. Tujuan pengujian adalah menemukan kesalahan-kesalahan terhadap system tersebut agar kemudian bisa diperbaiki.

5. Maintenance (Pemeliharaan)

Pemeliharaan merupakan salah satu hal yang paling penting. Sistem yang sudah digunakan oleh user harus dikembangkan dan pasti akan mengalami perubahan. dalam penelitian kali ini maintenance tidak digunakan.

\section{Hasil dan Pembahasan}

\subsection{Perancangan Sistem}

a. Diagram Konteks 


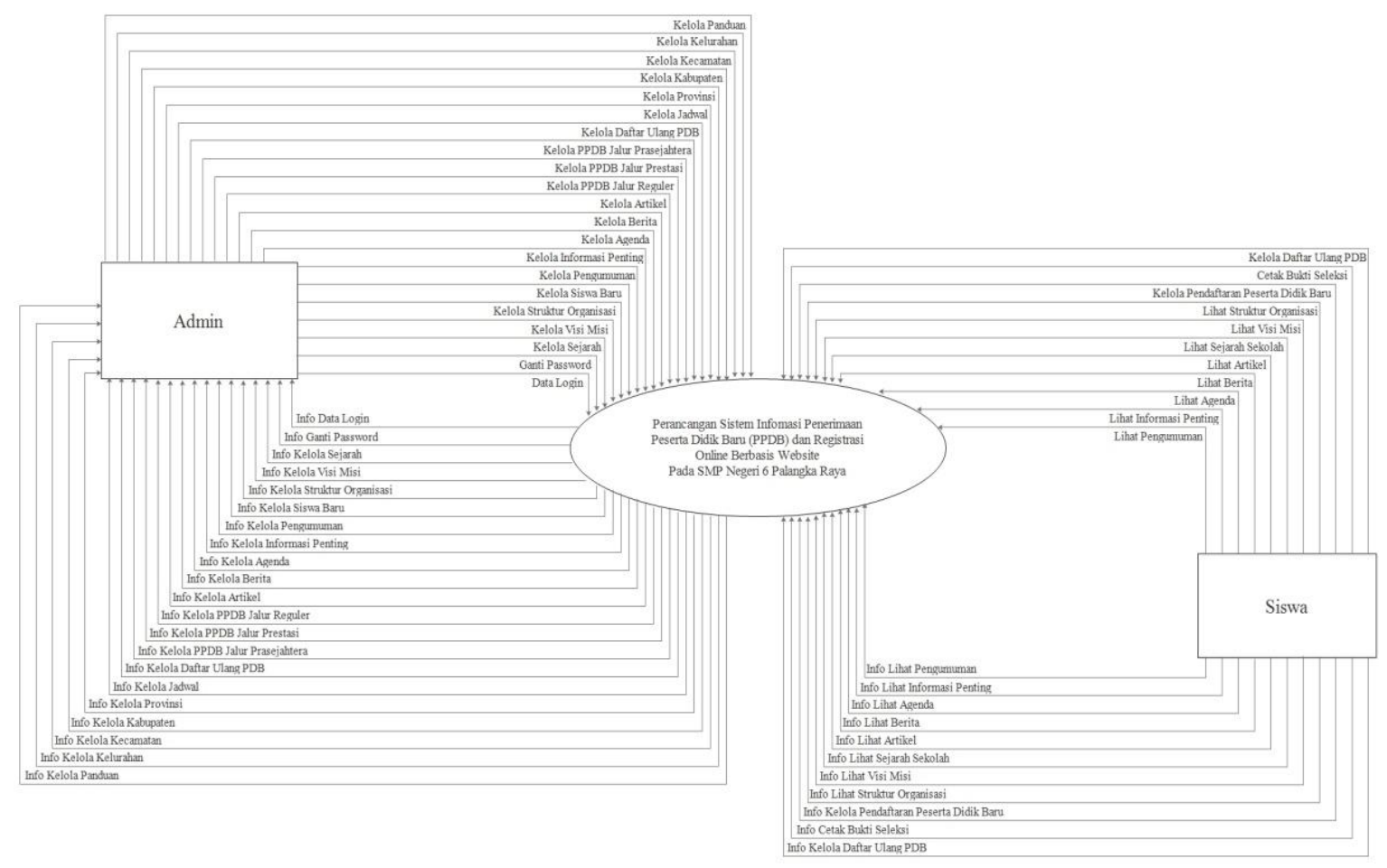

Gambar 2. Diagram Konteks

b. Data Flow Diagram Level 1 


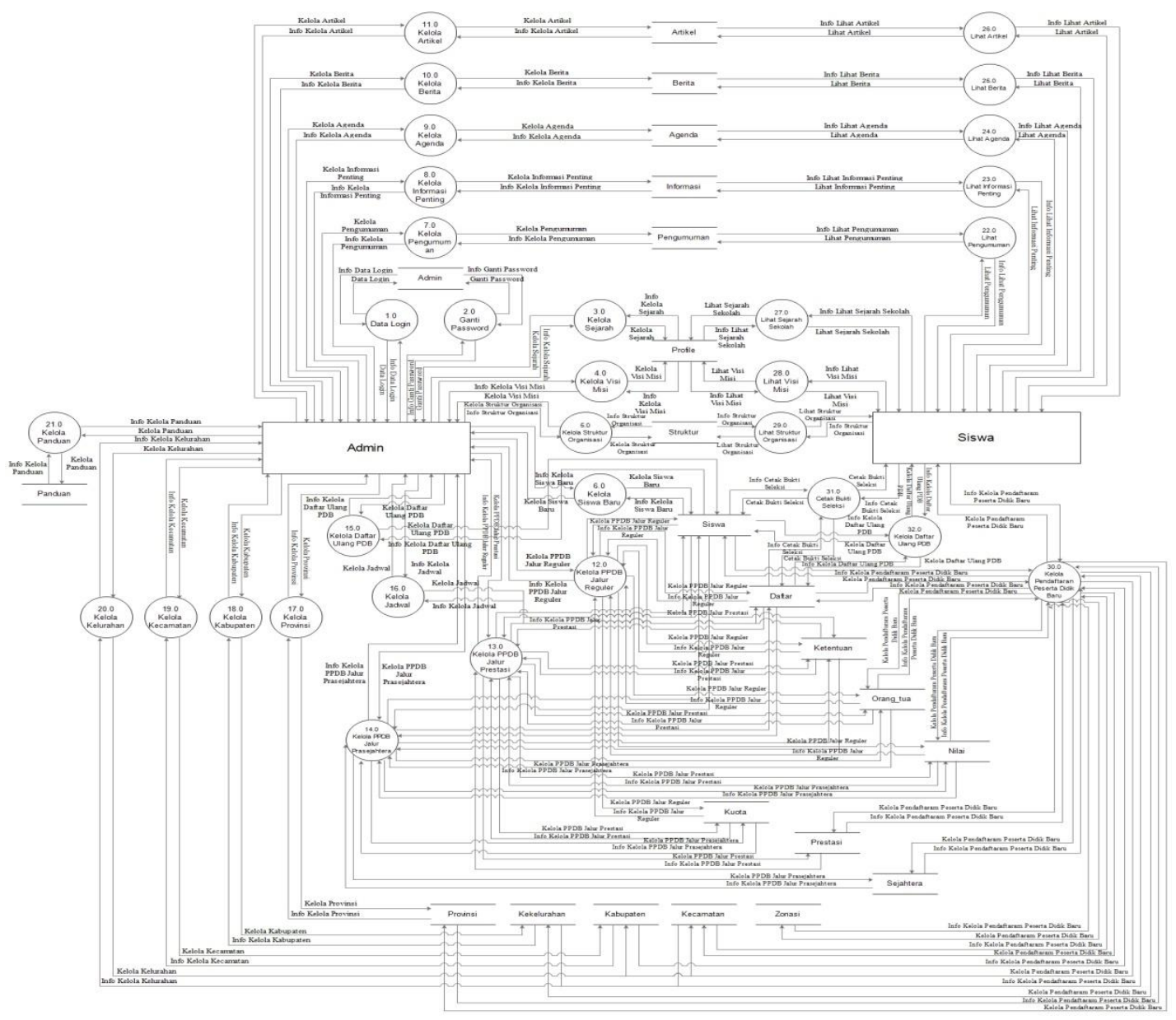

Gambar 3. Data Flow Diagram Level 1

\section{c. Entity Relationship Diagram}




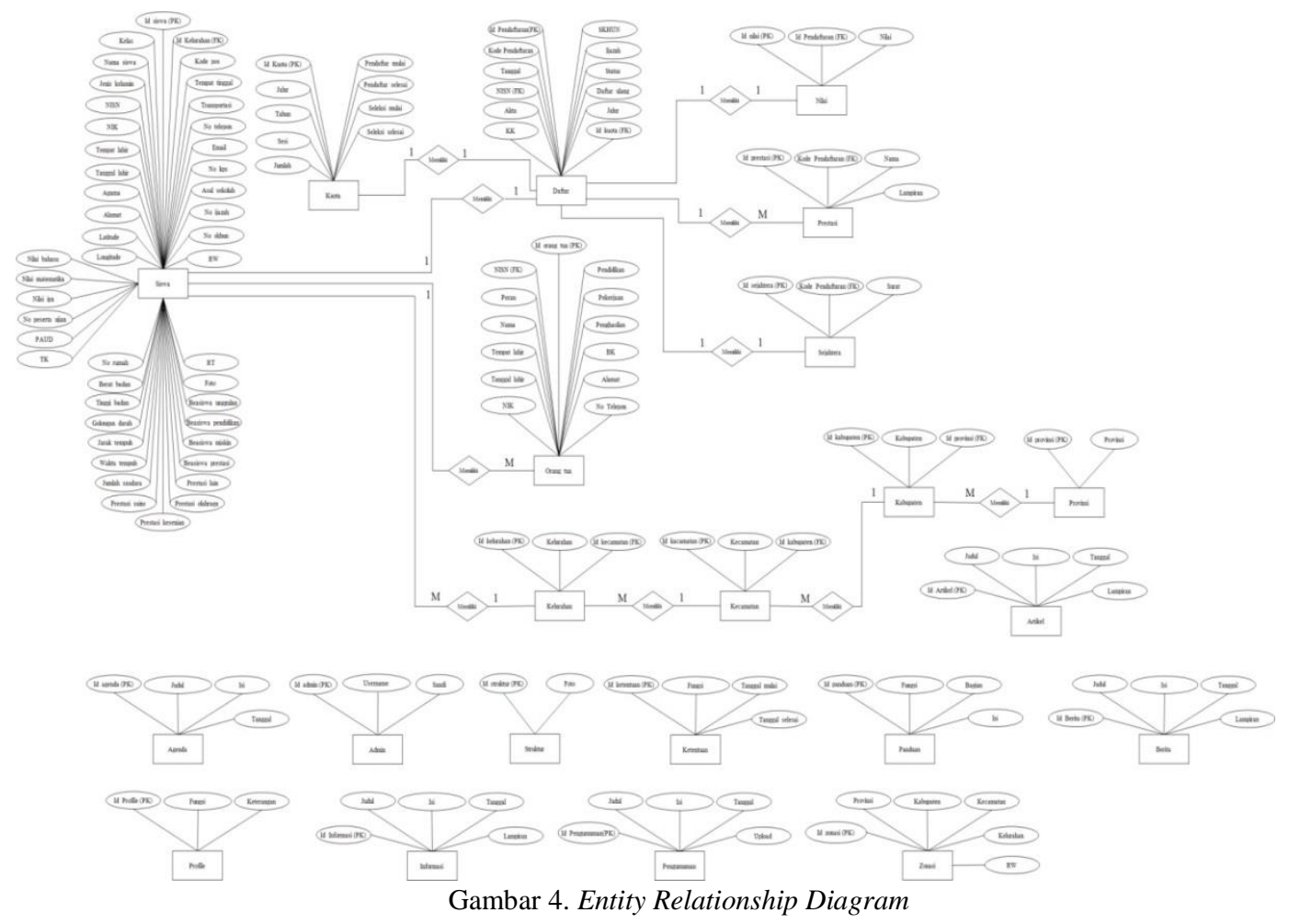

3.2. Perancangan Desain Sistem

a. Halaman Utama

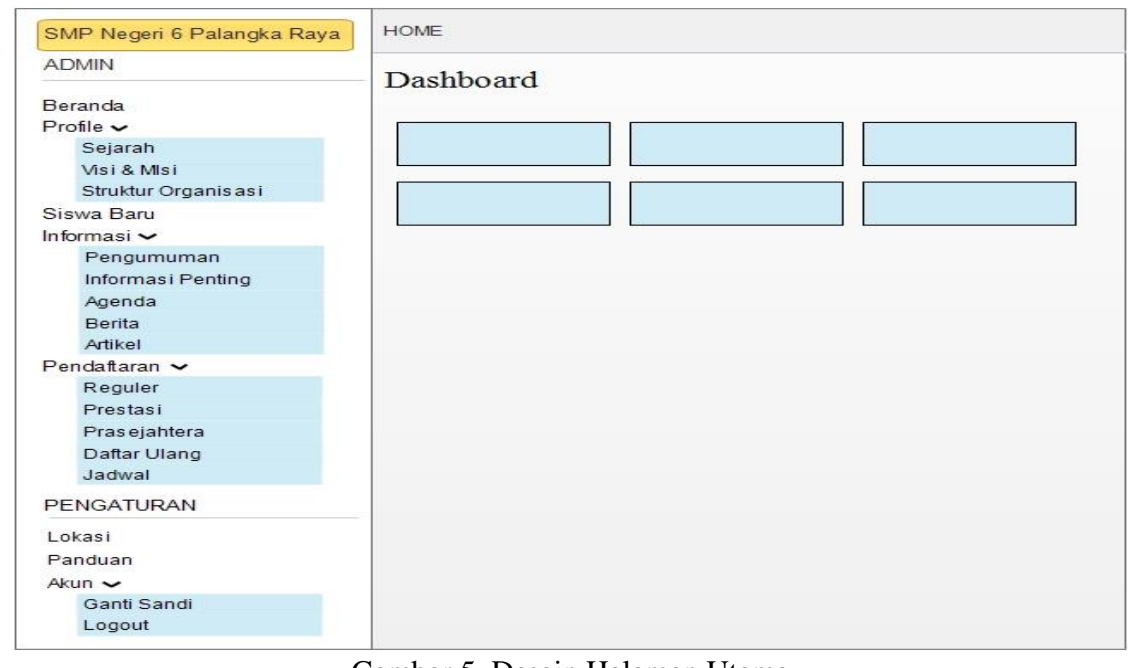

Gambar 5. Desain Halaman Utama

b. Halaman Pendaftaran Peserta Didik Baru

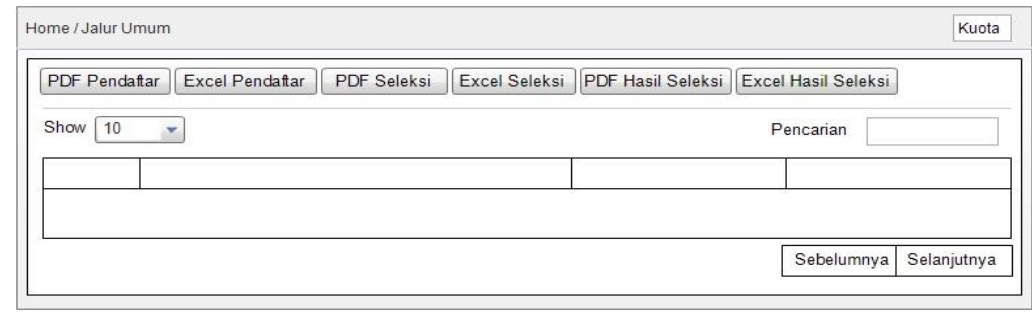

Gambar 6. Desain Halaman Pendaftaran Peserta Didik Baru 
c. Halaman Daftar Ulang

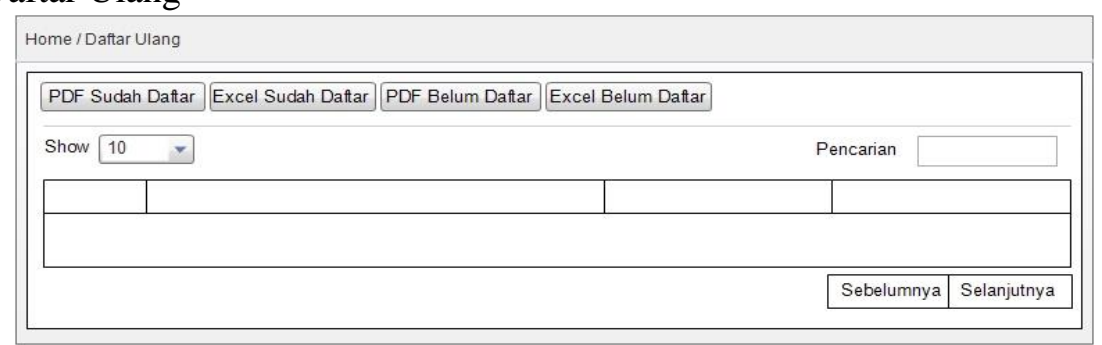

Gambar 7. Desain Halaman Daftar Ulang

d. Halaman Formulir Pendaftaran Peserta Didik Baru

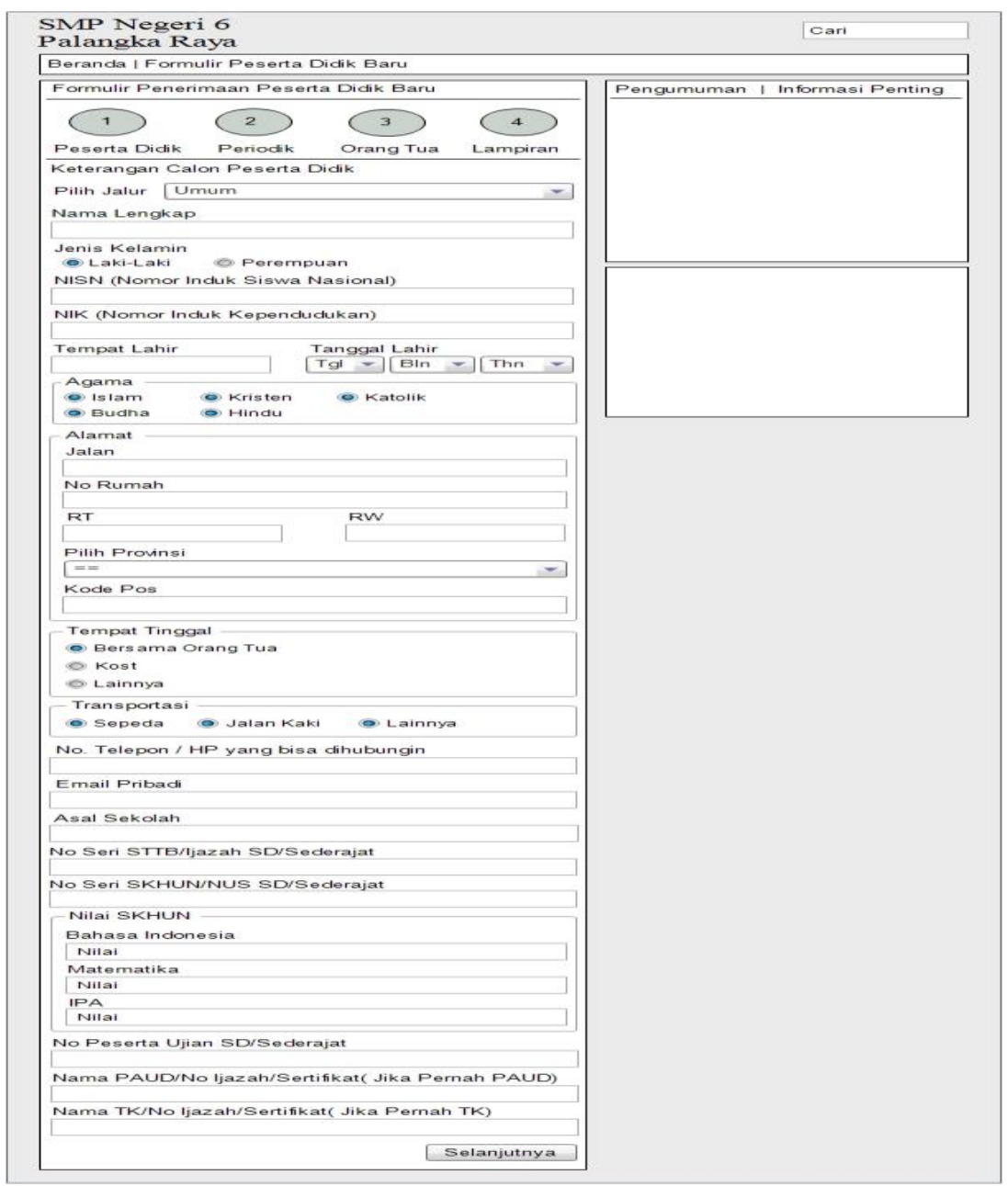

Gambar 8. Desain Halaman Formulir Pendaftaran Peserta Didik Baru

e. Halaman Formulir Pendaftaran Peserta Didik Baru Bagian Lampiran 


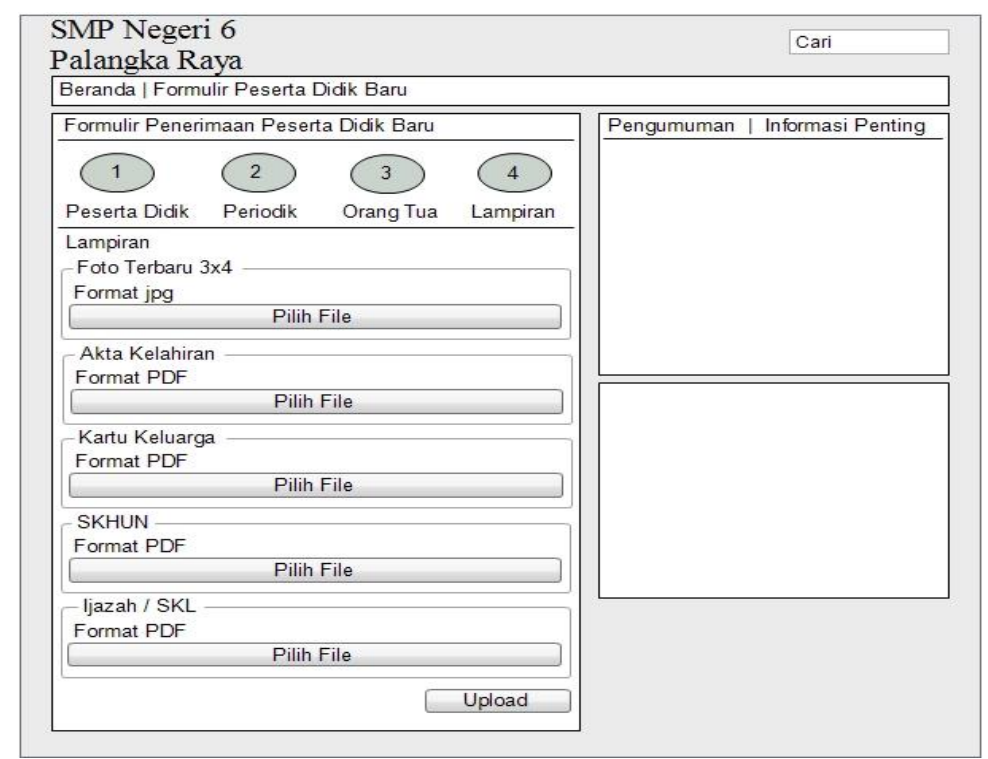

Gambar 9. Desain Halaman Formulir Pendaftaran Peserta Didik Baru Bagian Lampiran

\subsection{Hasil Tampilan Sistem}

Berikut merupakan tampilan antarmuka Sistem Informasi Pendaftaran Peserta Didik Baru dan Registrasi Online pada SMP Negeri 6 Palangka Raya. Hasil tampilan sistem ini merupakan implementasi dari perancangan desain sistem.

1. Implementasi Halaman Login

Halaman ini menampilkan form login yang harus diisi oleh pengguna ke dalam sistem.

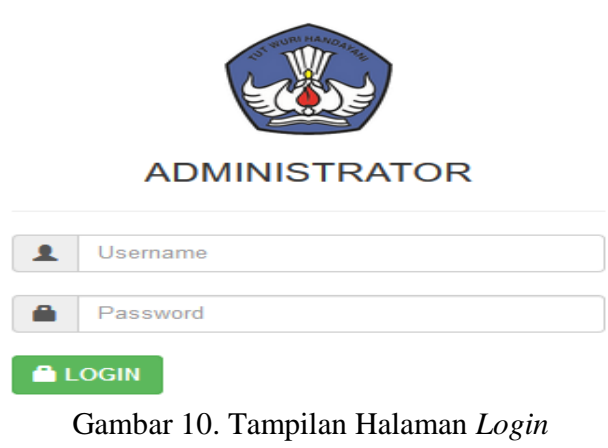

2. Implementasi Halaman Utama

Halaman ini merupakan tampilan halaman utama admin. 


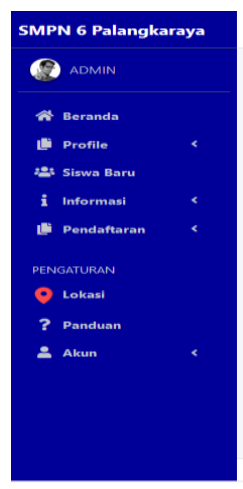

Dashboard
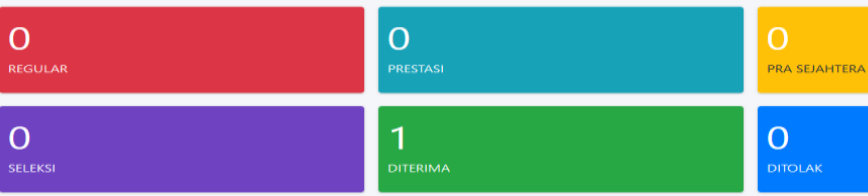

O

Gambar 11. Tampilan Halaman Utama

3. Implementasi Halaman Pendaftaran Peserta Didik Baru
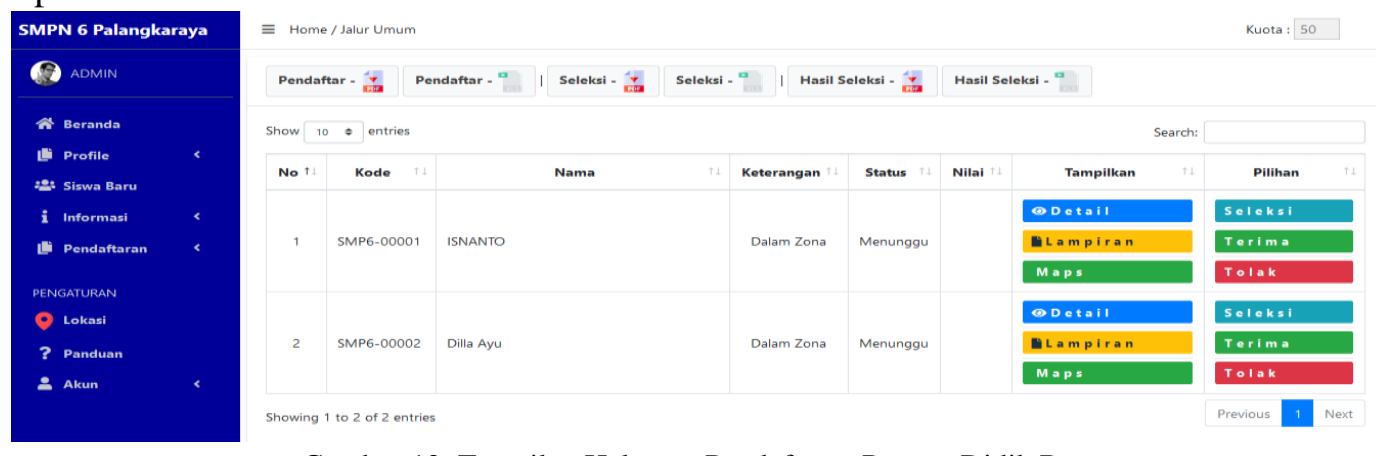

Gambar 12. Tampilan Halaman Pendaftaran Peserta Didik Baru

4. Implementasi Halaman Daftar Ulang

\begin{tabular}{|c|c|}
\hline \multicolumn{2}{|c|}{ SMPN 6 Palangkaraya } \\
\hline ADMIN & \\
\hline Â Beranda & \\
\hline LE Profle & - \\
\hline 20: Siswa Baru & \\
\hline i Informasi & - \\
\hline Lt Pendaftaran & 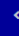 \\
\hline pengaturan & \\
\hline ○ Lokasi & \\
\hline
\end{tabular}

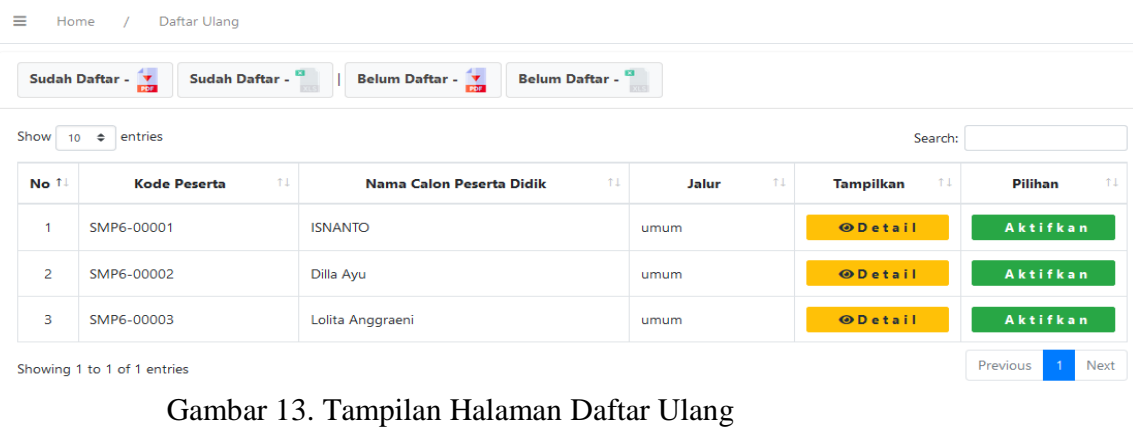

5. Implementasi Halaman Formulir Pendaftaran Peserta Didik Baru

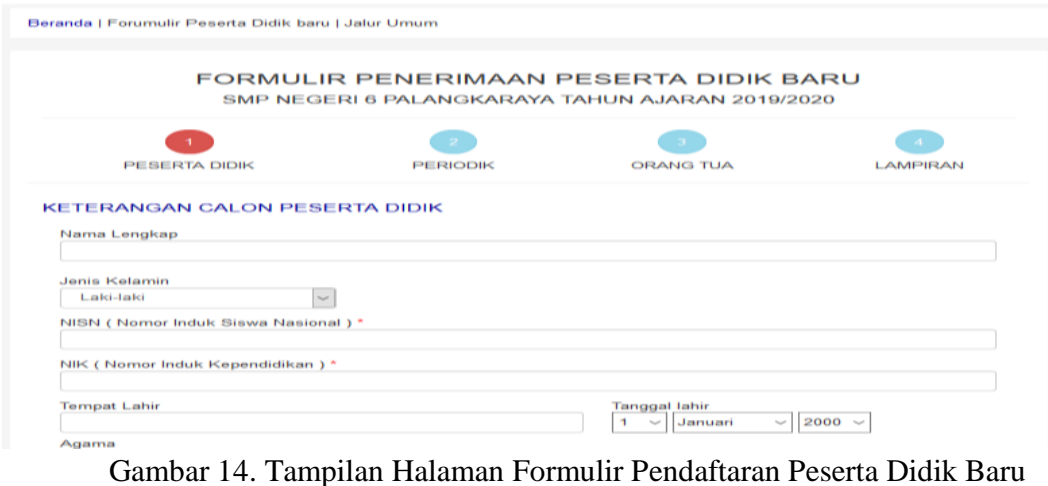

Gambar 14. Tampilan Halaman Formulir Pendaftaran Peserta Didik Baru 
6. Implementasi Halaman Formulir Pendaftaran Peserta Didik Baru Bagian Lampiran

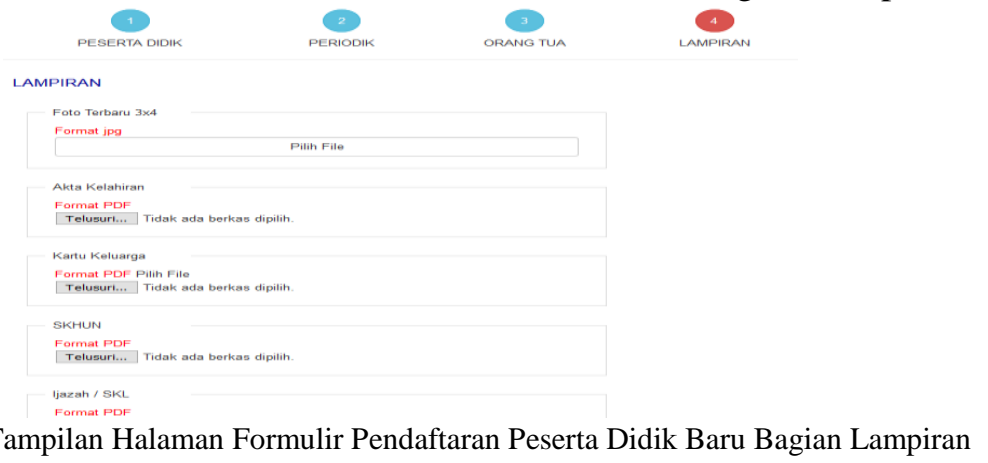

\section{Kesimpulan}

Kesimpulan dari penelitian ini berdasarkan rumusan masalah adalah untuk merancang sistem informasi penerimaan peserta didik baru (PPDB) dan registrasi online berbasis website pada SMP Negeri 6 Palangka Raya menggunakan metodologi penelitian waterfall.

Tahapan metodologi waterfall yang digunakan adalah analisis, design, implementation dan pengujian. Pada tahap analisis dilakukan analisa hal-hal yang diperlukan untuk mengetahui dengan jelas permasalahan dan kekurangan sistem yang sedang berjalan. Pada Tahap Design dilakukan desain sistem menggunakan DFD (Data Flow Diagram) Pada tahapan Implementation menggunakan bahasa pemrograman PHP, pengelolaan data menggunakan database MySQL dan Xampp sebagai server. Pada Tahap Testing dilakukan pengujian fitur-fitur yang ada pada website menggunakan metode black box.

Hasil dari pengujian blackbox pada sistem dapat diketahui bahwa fitur-fitur yang ada pada sistem informasi penerimaan peserta didik baru dan registrasi online dapat berfungsi seperti tujuan.

\section{Daftar Pustaka}

[1] Andre, "Pengertian dan Fungsi PHP Dalam Pemrograman Web, 2019.

[2] Astuti I. F., Khairina D. M., Febriani A., “'“Sistem Informasi Penerimaan Siswa Baru Sekolah Menengah Pertama Berbasis Web (Studi Kasus Kabupaten Kutai Kartanegara)", Jurnal Ilmiah Ilmu Komputer Vol. 9 No. 2, 2014

[3] Johan Aji Pribadi, “Sistem Informasi Pendaftaran Siswa Baru Berbasis Web”, Pacitan, 2015

[4] Dinas Pendidikan. Peraturan Kepala Dinas Pendidikan Kota Palangka Raya Nomor 420/500/BP/SMP.03/V/2018 Tahun 2018 Tentang Petunjuk Teknis Penerimaan Peserta Didik Baru (PPDB) Pada Sekolah Menengah Pertama Di Kota Palangka Raya Tahun Ajaran 2018/2019. Palangka Raya.

[5] Ranti Eka Putri. "Perancangan Sistem Informasi Registrasi Ulang Penerimaan Siswa Baru Berbasis Web”, 2017

[6] Oktaviyani D.E., KarolitaD., Licantik, Fransiska Y., "Sistem Informasi Pembagian Kelas Siswa Baru Menggunakan Metode K-Means Clustering Pada SMPN 9 Palangka Raya Berbasis Website", Jurnal Teknologi Informasi Vol. 12 No 2, 2018 